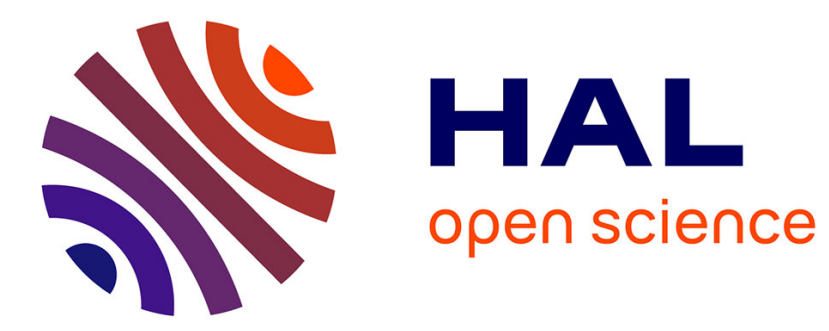

\title{
Development of a nomogram for individual preterm birth risk evaluation
}

Marion Gioan, Florence Fenollar, Anderson Loundou, Jean-Pierre Menard, Julie Blanc, Claude d'Ercole, Florence Bretelle

\section{- To cite this version:}

Marion Gioan, Florence Fenollar, Anderson Loundou, Jean-Pierre Menard, Julie Blanc, et al.. Development of a nomogram for individual preterm birth risk evaluation. Journal of Gynecology Obstetrics and Human Reproduction, 2018, 47 (10), pp.545-548. 10.1016/j.jogoh.2018.08.014 • hal-02006582

\section{HAL Id: hal-02006582 \\ https://hal-amu.archives-ouvertes.fr/hal-02006582}

Submitted on 11 Apr 2019

HAL is a multi-disciplinary open access archive for the deposit and dissemination of scientific research documents, whether they are published or not. The documents may come from teaching and research institutions in France or abroad, or from public or private research centers.
L'archive ouverte pluridisciplinaire HAL, est destinée au dépôt et à la diffusion de documents scientifiques de niveau recherche, publiés ou non, émanant des établissements d'enseignement et de recherche français ou étrangers, des laboratoires publics ou privés. 


\title{
Development of a nomogram for individual preterm birth risk evaluation
}

\author{
Marion Gioan ${ }^{\mathrm{a}}$, Florence Fenollar ${ }^{\mathrm{b}}$, Anderson Loundou ${ }^{\mathrm{c}}$, Jean-Pierre Menard ${ }^{\mathrm{d}}$, \\ Julie Blanc ${ }^{\mathrm{e}}$, Claude D'Ercole ${ }^{\mathrm{e}, \mathrm{f}}$, Florence Bretelle $\mathrm{e}^{\mathrm{e}, \mathrm{f} *}$ \\ ${ }^{a}$ CHG Sainte-Musse, 54, rue Henri-Sainte-Claire-Deville, 83100 Toulon, France \\ ${ }^{\mathrm{b}}$ Unité de recherche sur les maladies infectieuses tropicales et emergentes, UM63, CNRS 7278, IRD 198, INSERM 1095, 13000 Marseille, France \\ ${ }^{\mathrm{c}}$ Medical Evaluation, Department of Public Health, Assistance publique-hôpitaux de Marseille, AMU, Aix-Marseille Université, 13000 Marseille France \\ ${ }^{\mathrm{d}}$ Conseil départemental du Val-de-Marne, 94000 Créteil, France \\ e Department of Gynaecology and Obstetrics, Gynepole, AP-HM, Assistance publique-hôpitaux de Marseille, 13000 Marseille, France \\ ${ }^{\mathrm{f}}$ AMU, Aix-Marseille Université, 13000 Marseille, France
}

\section{A R T I C L E I N F O}

\section{Article history:}

Received 9 May 2018

Received in revised form 16 July 2018

Accepted 20 August 2018

Available online 24 August 2018

\section{Keywords:}

Premature birth

Nomogram

High risk

Asymptomatic

Bacterial vaginosis

Short cervix

Late miscarriage

\begin{abstract}
A B S T R A C T
Objective. - This study aimed to develop a new tool for personalised preterm birth risk evaluation in high-risk population.

Study design. - 813 high-risk asymptomatic pregnant women included in a French multicentric prospective study were analysed. Clinical and paraclinical variables, including screening for bacterial vaginosis with molecular biology, cervical length, have been used to create the nomogram, based on the logistic regression model. The validity was checked by bootstrap. A downloadable calculator was build. Results. - Nine risk factors were included in this model: history of late miscarriage and/or preterm delivery, active smoking, ultrasound cervical length, term of pregnancy at screening, bacterial vaginosis, premature rupture of membranes, daily travel more than $30 \mathrm{~min}$. Discrimination and calibration of the nomogram revealed good predictive abilities. The area under the receiver operating characteristic curve was 0.77 (95\% CI; 0.72-0.81). The mean absolute error was 0.018 , which showed proper calibration. The optimal risk threshold was $23.2 \%$ with a sensitivity of $74 \%$, a specificity of $72.7 \%$ and a predictive negative value of $90.6 \%$.

Conclusion. - The nomogram can help to better define individual preterm birth risk in high-risk pregnancies.
\end{abstract}

(c) 2018 Elsevier Masson SAS. All rights reserved.

\section{Introduction}

Preterm Birth (PB) remains the cause of neonatal morbidity and mortality in developed countries with up to $9 \%$ of pregnancies word wile [1]. In Europe PB occurs in 4.1 to $8.2 \%$ of birth leading to maternal prolong hospitalisations and treatments especially in high risk pregnancies [2,3]. Based on the definition, an asymptomatic pregnant woman with a history of $\mathrm{PB}$ or late miscarriage is considered at high risk for PB. Ultrasonographic cervical measurement is the standard gold to evaluate this risk. The risk depends on cervical length and gestational age at measurement [4]. The addition

\footnotetext{
* Corresponding author. Unité de recherche sur les maladies infectieuses tropicales et emergentes, UM63, CNRS 7278, IRD 198, INSERM 1095, 13000 Marseille, France

E-mail addresses: melkorsa@gmail.com (M. Gioan), florence.bretelle@ap-hm.fr (F. Bretelle).
}

of risk factor for the evaluation of PB risk could be a clue to improve the prediction of PB risk. For example Bacterial vaginosis (BV) is a risk factor for obstetrical complications [5,6]. The detection by molecular biology of microorganisms present in BV is a new diagnostic approach [7,8]. Ménard et al showed that the time to delivery was shorter when high atopobium vaginal load was detected in a high risk population $[8,9]$. No reliable predictive method exists today to define the risk of PB in high-risk pregnancies [10].

The nomogram is the graphic representation of the probability for each patient of an event. With this model, the risk calculation is simple, reproducible and personalised. Two recent studies proposed an assessment of PB risk in high-risk populations $[11,12]$. Unfortunately, their calculations did not incorporate most of the variables recognised as risk factors for $\mathrm{PB}$, such as vaginal swab results, history of adverse event or maternal smoking. Our study aim was to develop a new tool to evaluate individual risk for $\mathrm{PB}$ in a high-risk population. 


\section{Materials and methods}

\section{Target population}

The established nomogram has been created from the database of a prospective multicentric French cohort [13]. Pregnant women, who are 14 to 34 weeks (wks) pregnant, admitted for prenatal care in eight French teaching hospitals (among them two level II and six level III, all were public hospital except one), wishing to participate in the study, were eligible.

Taking into account a $30 \%$ proportion of preterm births before 37 weeks in our high risk population, a sample size of 690 women should show a hazard ratio (HR) of approximately 3.3 for Atopobium vaginae at a power at 80 . With lost to follow-up patients and missing data (estimated at 20\%) into account, 820 women is required.

\section{Inclusion criteria}

The patients included were older than 18 years and at risk for PB. This risk was defined as the existence of a short cervix (a cervical length $<25 \mathrm{~mm}$ measured by transvaginal ultrasound) and/or an obstetric history: history of preterm birth and/or late miscarriage (spontaneous expulsion of a pregnancy $\geq 14$ and $<22$ wks).

The exclusion criteria were: multiple pregnancies, treated hypertension, foetal malformation, antiphospholipid syndrome, diabetes, pre-eclampsia, renal disease, any auto-immune disease, or an antibiotic treatment in the past 7 days.

A complete medical examination and interrogation collected the demographic data, medical history (age, parity, body mass index, smoking during pregnancy, obstetric history, and current pregnancy data) and the clinical characteristics of each patient (uterine contractions, clinical signs of BV or premature rupture of membranes).

Vaginal sample and ultrasound measurement of the cervical length were performed. Gestational age was determined from the date of the last menstrual period or on the first trimester ultrasound in case of a one-week lag. The daily travel time data was collected and divided into two groups: more or less than 30 min. Obstetric and neonatal outcomes were collected in the postpartum period through consultation of medical files.

\section{Bacteriological analysis}

The bacteriological analysis was performed with self-collected vaginal swabs. Menard et al. [14] demonstrated the validity and reliability of this method versus practitioner-collected swab for molecular quantification. Each vaginal sample received a molecular biology analysis based on quantitative PCR. The results were blinded for the medical team of obstetricians. The organisms targeted by quantitative PCR and selected in our study were $A$. vaginae and Gardnerella vaginalis. Molecular quantification of $A$. vaginae $\geq 10^{8}$ copies $/ \mathrm{ml}$ and $/$ or $G$. vaginalis $\geq 10^{9}$ copies $/ \mathrm{ml}$ has been described as common in women with BV flora [8]. The trial was registered at ClinicalTrials.gov (identifier NCT00484653), and funded by the national hospital clinical research program (Programme de Recherche Clinique, number 2007-A00069-44). "Le Comité de Protection des Personnes Sud Méditerranée V" approved the project (number 07.019). Analysis method was previously reported [13].

\section{Statistical analysis}

Statistical analysis was performed with the IBM SPSS Statistics version 20 software. The association between the variables selected in the preliminary study and the risk for PB was tested with univariate and multivariate logistic regression analyses. Logistic model calibration was assessed using the Hosmer-Lemeshow goodness-of-fit test to evaluate the discrepancy between observed and expected values. Odds ratios were reported with $95 \%$ confidence interval (CI 95\%). Qualitative variables were presented in the form of enrollment counts and percentages. Quantitative variables were expressed as mean \pm standard deviation. The retained and integrated variables were the term (expressed as weeks of gestation (wks)), history of preterm and late miscarriage, premature rupture of membranes, smoking, daily travel time, BV diagnosed with molecular biology, sonographic measurement of cervical length, and the combination of history of preterm birth and cervical length $<25 \mathrm{~mm}$. Discrimination, calibration, and nomogram were performed using the "rms" library of the R software (http://www.R-project.org) [15]. The predictive model was internally validated for calibration with bootstrap resampling. This compares predicted PB and actual PB probabilities. The calibration was studied with a $\chi^{2}$-test with two degrees of freedom. Discrimination was examined using the area under the receiver operating characteristic (ROC) curve (AUC), graphic representation of the false-positive rate based on the sensitivity of each model value. AUC $>0.8$ represents an excellent discriminating power, and is good when comprised between 0.7 and 0.8 [16]. An AUC of 0.5 is random. The AUC is associated with $95 \%$ confidence interval (CI). The optimal threshold value for the risk of $\mathrm{PB}$ is the point on the ROC curve that is furthest from the diagonal and that represents the zero contribution test [17]. All the tests were two-sided. The statistical significance was defined as $P<.05$.

\section{Results}

Study

Between July 2007 and April 2012, 813 patients were included. PCR scores were performed on 764 vaginal samples. Data results were reported elsewhere [13]. In brief, the mean maternal age was 29.4 years $( \pm 5.6)$ and the percentage of multiparous patients was $17.5 \%$. Mean gestational age of pregnancies at inclusion was $26.3( \pm 5.1)$ wks. A total of 220 patients (28.8\%) gave birth before $37 \mathrm{wks}$, a total of 142 patients had an obstetric history of $\mathrm{PB}$ or late miscarriage. Among them, 122 women (86\%) had a short cervix. A cervix length $<25 \mathrm{~mm}$ was observed in 622 patients without adverse event history. Based on molecular definition of BV, 70 (9.2\%) patients were BV carriers.

Among women who delivered prematurely, 24 (10.9\%) had BV versus 46 (8.5\%) in the group where women delivered at term.

\section{Predictive model of preterm birth risk in high-risk population}

The results of the univariate and multivariate analysis are listed in Table 1. A multivariate logistic regression analysis demonstrated significant and independent associations between delivery before

\section{Table 1}

Univariate and multivariate analysis of Preterm birth risk factors. OR, odds ratio; $\mathrm{aOR}$, adjusted $\mathrm{OR}$; $\mathrm{CI}$, confidence interval; $\mathrm{PB}$, preterm birth; PROM, premature rupture of membranes.

\begin{tabular}{|c|c|c|c|}
\hline Variables & OR [CI 95\%] & $P$ & aOR [CI 95\%]P \\
\hline History of PB & $1.5[1-2]$ & $0.05^{*}$ & $3.6[1.2-11] 0.019^{*}$ \\
\hline History of late miscarriage & $1.2[0.7-1.9]$ & 0.5 & $1.6[0.5-5] \quad 0.41$ \\
\hline Gestational age & $0.9[0.9-0.96$ & ]$<.001^{*}$ & $0.9[0.8-0.9] 0.002$ \\
\hline Bacterial vaginosis & $1.3[0.8-2.2]$ & 0.3 & $1.6[0.6-4] \quad 0.33$ \\
\hline Smoking during pregnancy & $1.2[0.8-1.7]$ & 0.3 & $1.5[0.8-2.9] 0.23$ \\
\hline Sonographic cervical length & $0.9[0.9-0.96$ & ] $<.001^{*}$ & "0.9[0.8-0.9]0.001" \\
\hline History of $\mathrm{PB}+$ cervical length & $1.9[1.2-2.8]$ & $0.002^{*}$ & $0.4[0.1-1.4] 0.16$ \\
\hline Day travel time $>30 \mathrm{~min}$ & $1.4[1.00-1.9$ & $0.05^{*}$ & $2.6[1.4-4.9] 0.002^{*}$ \\
\hline PROM & $2.3[1.3-4.1]$ & $0.002^{*}$ & " $3.6[1.7-7.5] 0.001^{*}$ \\
\hline
\end{tabular}

Significant variables. 


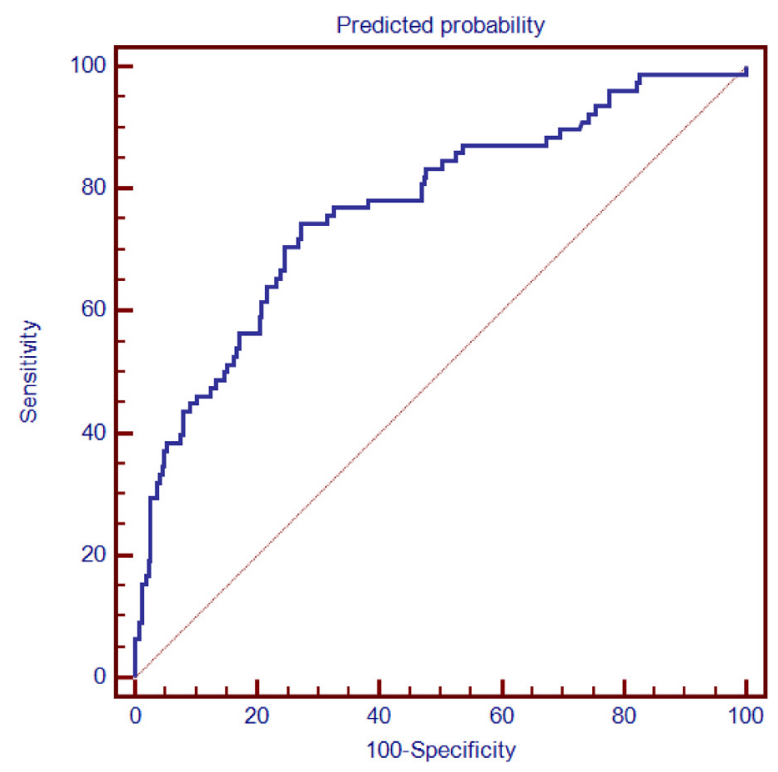

Fig. 1. Receiver Operating Characteristic curve: predictive model discrimination.

37 wks and sonographic cervical length, history of preterm birth, early gestational age at inclusion, premature rupture of membranes (PROM), and superior daily travel time of $30 \mathrm{~min}$. History of late miscarriage, combination of history of preterm birth and cervical length $<25 \mathrm{~mm}$, smoking during pregnancy and molecular diagnosis of BV were not associated with PB in our cohort, although these variables were significantly associated with a PB in a univariate analysis in the preliminary study. The literature recognizes these variables as risk factors for $\mathrm{PB}$. We have chosen to integrate these elements into the calculator. The AUC after bootstrap for the validation set was 0.77 (95\% CI; 0.72-0.81) (Fig. 1).

We used 500 bootstrap resamples for internal validation of accuracy estimates and to reduce overfit bias. The mean absolute error was 0.018. The maximum error was 0.0682. The mean squared error was 0.00051 . It represents the quality of measure of an estimator, as a result close to zero shows good calibration. We have therefore developed a nomogram to predict individual preterm birth risk in asymptomatic high-risk population (Fig. 2).

The optimal predictive value of the PB risk in high-risk populations has been determined from the ROC curve. The optimal probability threshold is $23.2 \%$ which offers different thresholds depending on statistical variables (Table 2 ). Prioritizing sensitivity to determine the threshold to use seems essential. Its use in clinical practice will allow minimising the rate of false-negative results.

\section{Discussion}

The present study developed a new predictive model for assessing the individual risk of $\mathrm{PB}$ in a high-risk population. Our nomogram evaluates a probability score based on the main well known risk factors of spontaneous PB and includes newly other risk factors. In our study according to literature [18], cervical length was one of the strongest risk factor for PB with the history of

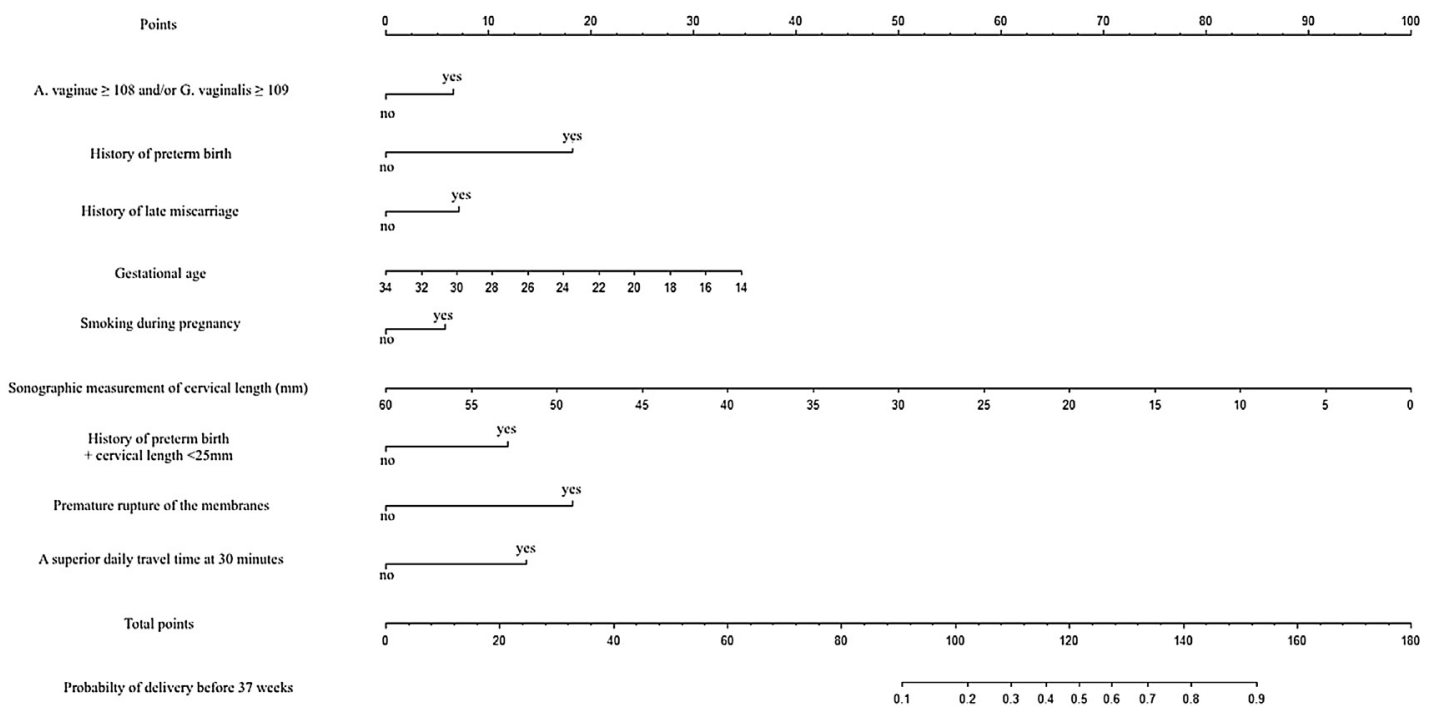

Fig. 2. Nomogram.

Table 2

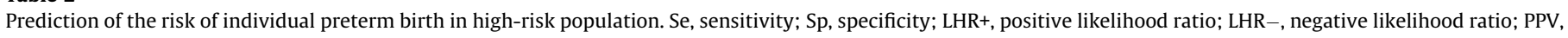
positive predictive value; NPV, negative predictive value; $95 \% \mathrm{CI}, 95 \%$ confidence interval.

\begin{tabular}{|c|c|c|c|c|c|c|}
\hline $\begin{array}{l}\text { PB rate (\%) } \\
{[95 \% \mathrm{CI}]}\end{array}$ & 8 & 15 & 23,2 & 30 & 55 & 74 \\
\hline Se & $100(95.4-100)$ & $82(71.7-89.8)$ & $74(63.2-83.6)$ & $56(44.7-67.6)$ & $23(14.3-34)$ & $6.4(2-14)$ \\
\hline Sp & $0(0.0-1.4)$ & $52.3(46-58.4)$ & $72.7(67-78)$ & $80.7(75.4-85.3)$ & 97.3 (94.6-99) & $100(98.6-100)$ \\
\hline LHR+ & $1(1.0-1.0)$ & $1.7(1.5-2)$ & $2.7(2.2-3.5)$ & $2.92(2.1-4.0)$ & $8.7(3.8-20.1)$ & NA \\
\hline LHR- & NA & $0.34(0.2-0.6)$ & $0.35(0.2-0.5)$ & $0.54(0.4-0.7)$ & $0.79(0.7-0.9)$ & $0.94(0.9-1.0)$ \\
\hline PPV & $22.8(18.7-27.5)$ & $33.5(27.2-40.5)$ & $44.6(36.3-53.12)$ & $45.8(36.2-55.8)$ & $72(52.4-85.7)$ & $100(56.5-100)$ \\
\hline NPV & $\mathrm{NA}$ & $90.7(85-94.4)$ & $90.6(85.8-93.8)$ & $86.2(81.31-89.9)$ & $81(76.4-85)$ & $78.3(73.6-82.4)$ \\
\hline
\end{tabular}


previous PB, PROM and long daily travel time. Some of the latest variables have never been used in a nomogram before. For example our results show an independent association between daily travel time and the risk of PB and was included in the model. Active smoking was also included in the model, even if non-significant in our results because of its previously was reported an association with PB (OR: 1.27, 95\% CI: 1.21-1.33) [19]. Previous PB was a strong and independent risk factor for $\mathrm{PB}$ in our study as previously reported in a meta-analysis with an absolute recurrence risk of 20.2\% (95\% CI: 19.9-20.6) [2]. PROM was an independent and strong risk factor for PB in our study and but had previously been included in a risk-calculating nomogram $[11,12]$.

In our model bacterial vaginosis was included even if it did not increase the risk for PB after multivariate analysis. The association between BV and PB has been previously reported, with a shorter time to delivery, reason why it was included in the model. A pregnant woman carrying BV has twice the risk of giving birth prematurely (OR: 2.16, 95\% CI: 1.56-3.00) [20], especially if screening was performed early during pregnancy [6]. In this situation the risk of late miscarriage is six times higher (OR: 6.32; 95\% CI: 3.65-10.94) [20]. Nevertheless the screening and treatment of asymptomatic BV in low-risk patients are not recommended and remain controversial for high-risk patients [21,22]. Because of heterogeneous BV definition, treatment, gestational age at screening. While waiting for the results of an on-going study [23], BV screening and treatment are recommended for the sub-population of asymptomatic patients with a history of adverse events in a mother-foetal infectious context [24].

A reliable screening tool should help for optimal management. The better identification of high-risk PB patients by using a predictive tool could limit medical costs. This could help also to decide the time of corticosteroids in order to avoid too early or repeated treatments that could be inefficient or dangerous for children [25].

Our predictive tool has been created based on a multicentric study performed with a large French cohort of patients. It could therefore be reproducible in high risk population. Until now, the only recommended monitoring tool was the length of the cervix or the foetal fibronectin between 16 and 22 wks [26,27]. Our model proposes to personalise the calculation of $\mathrm{PB}$ risk with additional risk factors.

Our study has some limits. To begin the use of molecular biology cannot be set up everywhere at the moment. Our model has not been validated on an independent population. We have used the re-sampling by bootstrap technique to counter the lack of external validity. The internal validity of our nomogram is improved by a high number of repetitions. Unfortunately, a tool is not applicable to patients at risk of preterm delivery for multiple pregnancy or uterine malformation. The low-risk population and induced labour are also not concerned. Other risk factors as the number of previous PBs, particularly in case of successive events, and the gestational of delivery of the previous PB could have been also included in order to improve accuracy of the nomogram [28].

\section{Conclusion}

An innovative calculator tool was developed in order to better define the individual risk of $\mathrm{PB}$ in high risk pregnancies. The accuracy of our predictive tool for the risk of $\mathrm{PB}$ should be further evaluated in a prospective study.

\section{References}

[1] Goldenberg RL, Culhane JF, Iams JD, Romero R. Epidemiology and causes of preterm birth. Lancet 2008;371:75-84

[2] Kazemier B, Buijs P, Mignini L, Limpens J, de Groot C, Mol B, et al. Impact of obstetric history on the risk of spontaneous preterm birth in singleton and multiple pregnancies: a systematic review. BJOG Int J Obstet Gynaecol 2014;121:1197-208.
[3] Delnord M, Mortensen L, Hindori-Mohangoo AD, Blondel B, Gissler M, Kramer MR, et al. Euro-Peristat Scientific Committee. International variations in the gestational age distribution of births: an ecological study in 34 high-income countries. Eur J Public Health 2017.

[4] Haute Autorité de Santé. Mesure de la longueur du canal cervical du col de l'utérus par échographie par voie vaginale. Intérêt dans le pronostic d'accouchement prématuré. Cadrage. Évaluation des actes professionnels. Paris: HAS; 2009.

[5] Menard JP, Bretelle F. Vaginose bactérienne et accouchement prématuré Gynécol Obstétr Fertil 2012;40:48-54.

[6] Leitich H, Bodner-Adler B, Brunbauer M, Kaider A, Egarter C, Husslein P. Bacterial vaginosis as a risk factor for preterm delivery: a meta-analysis. Am J Obstet Gynecol 2003;189:139-47.

[7] Menard J-P, Mazouni C, Fenollar F, Raoult D, Boubli L, Bretelle F. Diagnostic accuracy of quantitative real-time PCR assay versus clinical and Gram stain identification of bacterial vaginosis. Eur J Clin Microbiol Infect Dis 2010;29:1547-52.

[8] Menard J, Fenollar F, Henry M, Bretelle F, Raoult D. Molecular quantification of Gardnerella vaginalis and Atopobium vaginae loads to predict bacterial vaginosis. Clin Infect Dis 2008;47:33-43.

[9] Menard JP, Mazouni C, Salem-Cherif I, Fenollar F, Raoult D, Boubli L, et al. High vaginal concentrations of Atopobium vaginae and Gardnerella vaginalis in women undergoing preterm labor. Obstet Gynecol 2010;115:134-40.

[10] Compan C, Rossi A, Piquier-Perret G, Delabaere A, Vendittelli F, Lemery D, et al. Prédiction de la prématurité en cas de menace d'accouchement prématuré : revue de la littérature. J Gynécol Obstétr Biol Reprod 2015;44:740-51.

[11] Mailath-Pokorny M, Polterauer S, Kohl M, Kueronyai V, Worda K, Heinze G, et al. Individualized assessment of preterm birth risk using two modified prediction models. Eur J Obstet Gynecol Reprod Biol 2015;186:42-8.

[12] Allouche M, Huissoud C, Guyard-Boileau B, Rouzier R, Parant O. Development and validation of nomograms for predicting preterm delivery. Am J Obstet Gynecol 2011;204. 242.e1-8.

[13] Bretelle F, Rozenberg P, Pascal A, Favre R, Bohec C, Loundou A, et al. High Atopobium vaginae and Gardnerella vaginalis vaginal loads are associated with preterm birth. Clin Infect Dis 2015;60:860-7.

[14] Menard J-P, Fenollar F, Raoult D, Boubli L, Bretelle F. Self-collected vaginal swabs for the quantitative real-time polymerase chain reaction assay of Atopobium vaginae and Gardnerella vaginalis and the diagnosis of bacterial vaginosis. Eur J Clin Microbiol Infect Dis 2012;31:513-8.

[15] R: The R Project for Statistical Computing; n.d. https://www.r-project.org/ [accessed 19.02.17]

[16] Swets JA. Measuring the accuracy of diagnostic systems. Science 1988;240:1285.

[17] Delacour H, Servonnet A, Perrot A, Vigezzi JF, Ramirez JM. La courbe ROC (receiver operating characteristic): principes et principales applications en biologie clinique. Ann Biol Clin (Paris) 2005;63:145-54.

[18] Crane JMG, Hutchens D. Transvaginal sonographic measurement of cervical length to predict preterm birth in asymptomatic women at increased risk: a systematic review. Ultrasound Obstet Gynecol 2008;31:579-87.

[19] Shah NR, Bracken MB. A systematic review and meta-analysis of prospective studies on the association between maternal cigarette smoking and preterm delivery. Am J Obstet Gynecol 2000;182:465-72. http://dx.doi.org/10.1016 S0002-9378(00)70240-7.

[20] Leitich H. Kiss H. Asymptomatic bacterial vaginosis and intermediate flora as risk factors for adverse pregnancy outcome. Best Pract Res Clin Obstet Gynaecol 2007;21:375-90.

[21] Morales WJ, Schorr S, Albritton J. Effect of metronidazole in patients with preterm birth in preceding pregnancy and bacterial vaginosis: a placebocontrolled, double-blind study. Am J Obstet Gynecol 1994;171:345-7. discussion 348-349.

[22] Brocklehurst P, Gordon A, Heatley E, Milan SJ. Antibiotics for treating bacterial vaginosis in pregnancy. In: The Cochrane Collaboration, editor. Cochrane Database Syst. Rev.. Chichester, UK: John Wiley \& Sons, Ltd; 2013.

[23] Bretelle F, Fenollar F, Baumstarck K, Fortanier C, Cocallemen JF, Serazin V, et al Screen-and-treat program by point-of-care of Atopobium vaginae and Gardnerella vaginalis in preventing preterm birth (AuTop trial): study protocol for a randomized controlled trial. Trials 2015;16:470.

[24] Brabant G. Vaginose bactérienne et prématurité spontanée. Recommandations pour la pratique clinique : prévention de la prématurité spontanée et de ses conséquences (hors rupture des membranes). J Gynécol Obstétr Biol Reprod 2016;45:1247-60.

[25] Murphy KE, Hannah ME, Willan AR, Hewson SA, Ohlsson A, Kelly EN, et al. Multiple courses of antenatal corticosteroids for preterm birth (MACS): a randomised controlled trial. Lancet 2008;372:2143-51.

[26] Sentilhes L, Sénat M-V, Ancel P-Y, Azria E, Benoist G, Blanc J, et al. Recommandations pour la pratique clinique : prévention de la prématurité spontanée et de ses conséquences (hors rupture des membranes)-Texte des recommandations (texte court). J Gynécol Obstétr Biol Reprod 2016:45:1446-56.

[27] DeFranco EA, Lewis DF, Odibo AO. Improving the screening accuracy for preterm labor: is the combination of fetal fibronectin and cervical length in symptomatic patients a useful predictor of preterm birth? A systematic review. Am J Obstet Gynecol 2013;208. 233.e1-6.

[28] Blanc J, Bretelle F. Outils prédictifs de l'accouchement prématuré dans une population asymptomatique à haut risque. J Gynécol Obstétr Biol Reprod 2016;45:1261-7. 